\title{
Anandamide Regulates Postnatal Development of Long- Term Synaptic Plasticity in the Rat Dorsolateral Striatum
}

\author{
Kristen K. Ade ${ }^{1}$ and David M. Lovinger ${ }^{2}$ \\ ${ }^{1}$ Department of Physiology and Biophysics, Georgetown University School of Medicine, Washington, DC 20007, and ${ }^{2}$ Laboratory for Integrative \\ Neuroscience, National Institute on Alcohol Abuse and Alcoholism, National Institutes of Health, Bethesda, Maryland 20892
}

\begin{abstract}
Long-term changes in synaptic efficacy produced by high-frequency stimulation (HFS) of glutamatergic afferents to the rat dorsolateral striatum exhibit heterogeneity during early stages of postnatal development. Whereas HFS most often induces striatal long-term potentiation (LTP) in rats postnatal day 12 (P12)-P14, the same stimulation tends to induce long-term depression (LTD) at ages P16-P34. Previous studies have shown that striatal LTD induction depends on retrograde endocannabinoid signaling and activation of the CB1 cannabinoid receptor. It is also known that levels of one of the primary endogenous CB1 receptor agonists, anandamide (AEA), increases during development in whole-brain samples. In the present study, we sought to determine whether this developmental increase in AEA also takes place in striatal tissue and whether increased AEA levels contribute to the postnatal switch in the response to HFS. We observed a pronounced increase in striatal levels of AEA, but not the other major endogenous cannabinoid 2-arachidonoylglycerol (2-AG), during the postnatal period characterized by the switch from LTP to LTD. Furthermore, application of synthetic AEA during HFS in field recordings of slices from P12-P14 rats allowed for induction of LTD whereas blocking the CB1 receptor during HFS in animals P16-P34 resulted in expression of LTP. However, blocking 2-AG synthesis with the DAG-lipase inhibitor tetrahydrolipstatin did not alter HFSinduced striatal LTD. In addition, synaptic depression produced by a synthetic CB1 agonist was similar across development. Together, these findings suggest that the robust developmental increase in striatal AEA may be the key factor in the emergence of HFS-induced striatal LTD.
\end{abstract}

Key words: endocannabinoid; basal ganglia; long-term depression; LTD; long-term potentiation; LTP; glutamate; development

\section{Introduction}

Activity-dependent long-term changes in synaptic efficacy at central synapses are thought to provide a cellular basis for learning and memory. The striatum, especially the dorsolateral (DL) subregion, appears to play an important role in habit learning (Barnes et al., 2005; Yin et al., 2005, 2006). Because the cortical input to striatal medium spiny neurons plays a central role in coordinating the output of the caudate/putamen, activitydependent changes at the corticostriatal synapse may underlie both motor learning and instrumental conditioning (Costa et al., 2004; Barnes et al., 2005).

Previous studies have shown that at least two forms of longterm plasticity can be induced in the dorsal striatum. Striatal long-term potentiation (LTP) is a long-lasting increase in synaptic efficacy that requires activation of NMDA-type glutamate receptors (Calabresi et al., 1992b; Partridge et al., 2000; Spencer and Murphy, 2000) and D1 dopamine receptors (Kerr and Wickens, 2001; Reynolds et al., 2001). Striatal long-term depression (LTD), however, is a long-lasting decrease in synaptic strength and depends on a number of converging factors including activation of

Received July 10, 2006; revised Jan. 28, 2007; accepted Jan. 29, 2007.

We thank Judith Harvey-White, Dr. George Kunos, and Josh Ohrtman for their technical assistance.

Correspondence should be addressed to David M. Lovinger, Laboratory for Integrative Neuroscience, National Institute on Alcohol Abuse and Alcoholism-National Institutes of Health, 5625 Fishers Lane, TS-13, Bethesda, MD 20892.

DOI:10.1523/JNEUROSCI.2916-06.2007

Copyright $\odot 2007$ Society for Neuroscience $\quad$ 0270-6474/07/272403-07\$15.00/0
D2 dopamine receptors (Calabresi et al., 1992a, 1997; Choi and Lovinger, 1997) and type I metabotropic glutamate receptors (Gubellini et al., 2001; Sung et al., 2001), increases in postsynaptic intracellular calcium involving activation of L-type calcium channels (Calabresi et al., 1992a, 1994; Choi and Lovinger, 1997), and postsynaptic endocannabinoid release leading to activation of CB1 cannabinoid receptors (Gerdeman et al., 2002), but not NMDA receptors (Lovinger et al., 1993). Both forms of plasticity are induced by high-frequency stimulation (HFS) of striatal afferents, but expression of LTP versus LTD varies as a function of postnatal age of the animals. HFS of the glutamatergic afferents to the DL striatum induces LTP during early rat postnatal development [postnatal day 12 (P12)-P14]. However, the same stimulation protocol predominantly induces LTD in the DL striatum of rats P15 and older (Partridge et al., 2000).

CB1 receptors are activated by the endogenous cannabinoid ligands anandamide (AEA) (Felder et al., 1993) and 2-arachidonoylglycerol (2-AG) (Stella et al., 1997). These lipid metabolites serve as retrograde signaling molecules, and postsynaptic release of at least one of the endocannabinoids is required for LTD induction (Gerdeman et al., 2002). CB1 receptor mRNA and protein are both present in the brain throughout rat prenatal and postnatal development (Berrendero et al., 1999). However, whole brain measurements in the rat have shown that levels of the AEA, but not 2-AG, increase during postnatal development (Berrendero et al., 1999; Di Marzo, 1999; Fernández-Ruiz et al., 2000).

In light of these findings, we hypothesized that the develop- 
mental shift in striatal plasticity in the rat results from an increase in AEA synthesis and release. In the present study, we combined electrophysiological recordings from striatal slices with measurements of striatal endocannabinoid levels to examine potential mechanisms involved in this developmental switch. We provide evidence for a developmental increase in AEA levels in striatal tissue and show that the level of striatal AEA determines the direction of synaptic plasticity induced by HFS.

\section{Materials and Methods}

Animals. Pregnant female rats were obtained from Charles River Laboratories (Kingston, NY). All rat pups used for this study were born in house and weaned at postnatal day 22. Animals were kept in a facility with a $12 \mathrm{~h}$ light/dark cycle at $21-22.5^{\circ} \mathrm{C}$ and were given food and water ad libitum. The date of birth in this study was designated as P0.

Slice preparation. Rats were decapitated and the brain was quickly removed over ice $(<45 \mathrm{~s})$ and placed in modified ice-cold artificial CSF (aCSF) containing the following (in mM): 194 sucrose, $30 \mathrm{NaCl}, 4.5 \mathrm{KCl}$, $1 \mathrm{MgCl}_{2}, 26 \mathrm{NaHCO}_{3}, 1.2 \mathrm{NaH}_{2} \mathrm{PO}_{4}$, and 10 D-glucose adjusted to $\mathrm{pH} 7.4$ by bubbling with $95 \% \mathrm{O}_{2} / 5 \% \mathrm{CO}_{2}$. Coronal sections containing the cortex and striatum ( $400 \mu \mathrm{m}$ thickness) were cut in this ice-cold aCSF using a Vibroslice (Campden Instruments, Loughborough, UK) and were transferred to a chamber maintained at room temperature and filled with the recording aCSF that contained the following (in mM): $124 \mathrm{NaCl}, 2$ $\mathrm{CaCl}_{2}, 4.5 \mathrm{KCl}, 1 \mathrm{MgCl}_{2}, 26 \mathrm{NaHCO}_{3}, 1.2 \mathrm{NaH}_{2} \mathrm{PO}_{4}$, and 10 D-glucose. The aCSF in the chamber was maintained at $\mathrm{pH} 7.4$ by continuously bubbling with $95 \% \mathrm{O}_{2} / 5 \% \mathrm{CO}_{2}$. Slices were allowed to equilibrate for $1 \mathrm{~h}$ before the electrophysiological experiments or tissue harvesting for the endocannabinoid measurements. All tissue harvesting was performed between the hours of 10:00 A.M. and 3:00 P.M. For preapplication experiments, slices were preincubated with $1 \mu \mathrm{M}$ tetrahydrolipstatin (THL) (Sigma, St. Louis, MO) for 60-120 min in the incubation chamber before recording.

Field-potential recordings. Slices were transferred to a heated recording chamber (maintained at $30-31^{\circ} \mathrm{C}$ ) and were completely submerged with continuous superfusion of the recording aCSF. Field-recording pipettes were made from borosilicate glass capillaries and pulled on a FlamingBrown micropipette puller. Pipettes were filled with the recording aCSF, and resistance typically ranged from 1 to $1.5 \mathrm{M} \Omega$. Twisted bipolar stimulating electrodes were placed in the white matter overlying the DL striatum such that no part of the stimulating electrode was touching the striatum. The recording electrodes were placed $\sim 2 \mathrm{~mm}$ away in the striatum where field potentials $\geq 0.8 \mathrm{mV}$ could be detected. Signals were amplified using an Axoclamp 2A amplifier, and the stimulation was generated by a Grass stimulator with an optical isolation unit. Data were digitized using a digidata with a low-pass filter of $3 \mathrm{kHz}$, a high-pass filter of $0.1 \mathrm{~Hz}$, and a gain of $1000 \times$. Before the recording, both the minimum stimulus intensity that evoked the maximum amplitude population spike (PS) field response and the intensity that evoked half the maximal amplitude were determined. During the recording period both before and after HFS, the half maximal intensity stimulation was used and stimuli were given at $20 \mathrm{~s}$ intervals.

LTP and LTD were induced by an HFS protocol of four $100 \mathrm{~Hz}$ trains of $1 \mathrm{~s}$ duration given $10 \mathrm{~s}$ apart. Stimulus intensity during HFS was increased to the minimum intensity that evoked the maximal field response.

Data analysis. For field-potential recordings, PS amplitudes as well as slopes were measured using pClamp software (Molecular Devices, Foster City, CA). In six early experiments, both the ratio of the amplitudes and the slopes of the population spikes before and after HFS were compared. Because no significant differences between the magnitudes of LTP or LTD were found when comparing the measurements of the slopes with measurements of the amplitudes, and because the physiological relevance of PS slope is not clear, we chose to measure only changes in amplitude for the remaining experiments. Comparisons of the N1 nonsynaptic field potential component (presumed to reflect a presynaptic fiber volley) before and after HFS served as internal control measures in each experiment to ensure that changes in PS amplitude were not an indirect result of decreased axonal activation or a general decrease in recording quality or slice health. Experiments in which N1 amplitude fluctuated by $>5 \%$ were excluded from analysis. The occurrence and magnitude of LTP and LTD in each experiment was determined by comparing the mean PS amplitudes from the last 12 traces $(4 \mathrm{~min})$ in the baseline recording with the last 12 traces of the experiment after HFS. All experiments were normalized such that the PS amplitude is expressed as a percentage of the PS amplitude observed during the baseline recording period \pm SEM. Significance was determined by two-way repeated measures ANOVA with Bonferroni post hoc tests unless otherwise noted, and $p<0.05$ was considered significant.

Endocannabinoid measurements. Slices were made in the same manner as for the electrophysiological experiments. The dorsal striatum was dissected out of the coronal section over ice and was transferred to and rapidly frozen on a small piece of aluminum foil laid over dry ice. All of the striatal tissue from a given rat was pooled to yield one sample per animal. The samples were maintained at $-80^{\circ} \mathrm{C}$ until further processing. The endocannabinoids were extracted as described previously (Wang et al., 2003). The samples were weighed and then transferred rapidly to a homogenizing tube containing $0.5 \mathrm{ml}$ ice-cold solution of 1:1 methanol/ Tris buffer $(50 \mathrm{~mm}), \mathrm{pH} 8.0$, that contained $7 \mathrm{ng}$ of deuterium4-AEA synthesized as described previously (Giuffrida et al., 2000). Synthetic AEA was obtained from Cayman Chemical (Ann Arbor, MI). Two milliliters of 2:1 chloroform/methanol and $0.5 \mathrm{ml}$ of Tris buffer, $\mathrm{pH} 8.0$, were added to each homogenate. Each homogenate was mixed using a vortex, and subsequently centrifuged at $-2^{\circ} \mathrm{C}$ at $(2000 \times g$ for $2 \mathrm{~min})$. The chloroform phase was recovered and transferred to a borosilicate tube and the water phase was extracted with $1 \mathrm{ml}$ ice-cold chloroform two more times. The combined extract was evaporated to dryness under a stream of nitrogen at room temperature, at which point the samples could be maintained at $-80^{\circ} \mathrm{C}$ until the next phase of processing. The dried residue was reconstituted in $110 \mu \mathrm{l}$ chloroform and $2 \mathrm{ml}$ acetone, mixed using a vortex, and centrifuged $\left(3000 \times g, 10 \mathrm{~min}\right.$ at $\left.-2^{\circ} \mathrm{C}\right)$. The supernatant was removed from the residual precipitated proteins and was evaporated to dryness under nitrogen at room temperature. The dry residues were reconstituted in $50 \mu \mathrm{l}$ ice-cold methanol of which $35 \mu \mathrm{l}$ was injected for analysis by liquid chromatography/in-line mass spectrometry (1100 series LC-MSD thermostated autosampler and column compartment; Agilent, Santa Clara, CA). Separation of the endocannabinoids was achieved by liquid chromatography using a guard column (Discovery HS C18; $2 \mathrm{~cm} \times 4.6 \mathrm{~mm}, 3 \mu \mathrm{m}$ ) at $32^{\circ}$ with a mobile phase of water/methanol/acetic acid (90:10:0.1, vol/vol/vol) at a flow rate of 1 $\mathrm{ml} / \mathrm{min}$ for $1.2 \mathrm{~min}$, from 1.2 to $3.2 \mathrm{~min}$ linear ramp to 15:85:01, and held at this ratio for $17 \mathrm{~min}$ followed by $5 \mathrm{~min}$ methanol/acetic acid (100:0.1). Tissue protein levels were determined using the BCA assay (Pierce, Rockford, IL).

\section{Results}

\section{Synaptic plasticity in the dorsolateral striatum is age dependent}

In agreement with previous findings (Partridge et al., 2000), HFS trains delivered to the glutamatergic cortical and thalamic afferents to the DL striatum in acute slices induced diverging forms of synaptic plasticity that depended on postnatal age. Lowfrequency $(0.05 \mathrm{~Hz})$ stimulation in the white matter induced stable population spikes that were followed for $10 \mathrm{~min}$ before HFS. Delivery of HFS induced LTP in 11 of 11 slices in slices made from $\mathrm{P} 13$ rats. The post-HFS PS amplitude averaged $160 \pm 10 \%$ of the baseline amplitude $30 \mathrm{~min}$ after the HFS $(p<0.001)$ (Fig. 1). In agreement with previous studies (Calabresi et al., 1992b; Partridge et al., 2000), induction of striatal LTP was blocked by application of the NMDA receptor antagonist, $50 \mu \mathrm{M}$ APV. The post-HFS PS amplitude averaged $82 \pm 14 \%$ of the baseline amplitude $30 \mathrm{~min}$ after the HFS in the presence of APV $(n=4)$. However, HFS induced LTD in eight of nine slices in slices from P16-P34 animals. The one slice that did not show LTD showed no change in response after the HFS and was recorded in a P16 
A

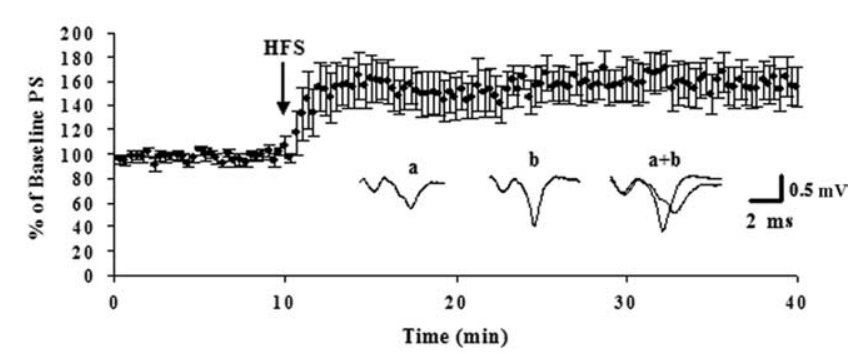

B

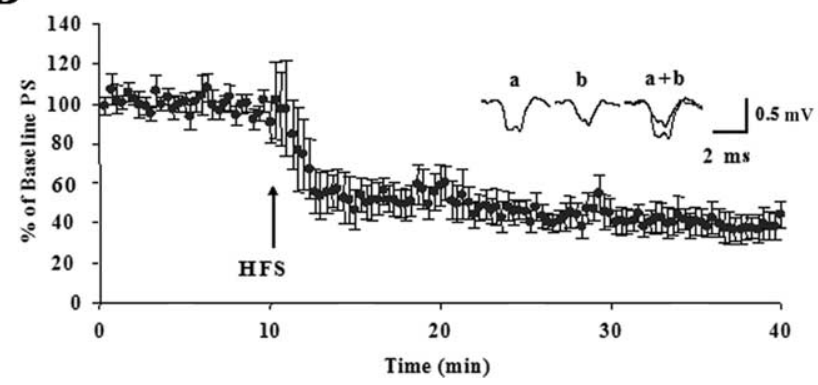

Figure 1. Synaptic plasticity in the rat DL striatum is age dependent. After obtaining a stable baseline at an intensity that resulted in a field potential recording of half the maximum amplitude for $10 \mathrm{~min}$, the HFS protocol was given and responses were followed for an additional 30 min. Time courses are presented as normalized PS amplitudes. The inset provides representative traces (average of 12 individual responses) from baseline recordings just before giving the HFS protocol (a), response 30 min after giving the HFS protocol (b), and overlay $(a+b) . A, H F S$ caused potentiation of the PS amplitude in P13 animals. The average response $30 \mathrm{~min}$ after the HFS was $160 \pm 10 \%$ SEM $(n=11)$ of the baseline PS amplitude. $\boldsymbol{B}$, HFS induced a depression of the PS amplitude in slices made from animals P16-P34. The average response $30 \mathrm{~min}$ after the HFS was $53 \pm 3 \%$ SEM $(n=9)$ of the baseline measure. Error bars indicate SEM.

animal. On average, the population spike amplitude was $53 \pm 3 \%$ of the baseline measure 30 min after HFS $(p<0.001)$ (Fig. 1). In agreement with previous reports (Ronesi et al., 2004), application of the CB1 antagonist SR $14171610 \mathrm{~min}$ after HFS could not reverse LTD. In three experiments, SR 141716 was washed on 30 min after HFS. In these experiments the PS amplitude $30 \mathrm{~min}$ after HFS and after 30 min of SR 141716 application were, on average, 39.5 and $41.0 \%$ of the baseline amplitude, respectively.

\section{Striatal anandamide levels increase during postnatal development}

Tissue levels of AEA increased markedly during postnatal development (Fig. 2). AEA levels increased by $1125 \%(p<0.001)$ between postnatal days 13 and 17, which corresponds to postnatal days when LTP (P13) and LTD (P17) were consistently seen. No changes in 2-AG levels were observed during this developmental time period (Fig. 2). Spontaneous isomerization of 2-AG to 1(3)-arachidonoylglycerol (1-AG) can occur during tissue processing (Stella et al., 1997) and, thus, we measured levels of $1-A G$ as well. Figure 2 shows no significant developmental changes in the combined total of 2-AG and 1-AG. Measurement of AEA levels as a function of tissue weight does not take into account possible changes in cellular material within tissue that likely occur during neuronal development (caused by extension of dendrites for example). Normalizing AEA levels to tissue protein content would correct for cellular changes. However, protein measurements could not be performed in the same samples used for the endocannabinoid measurements because the entire tissue sample was needed to obtain accurate AEA levels, and the lipid extraction protocol results in protein degradation. We thus per-
A
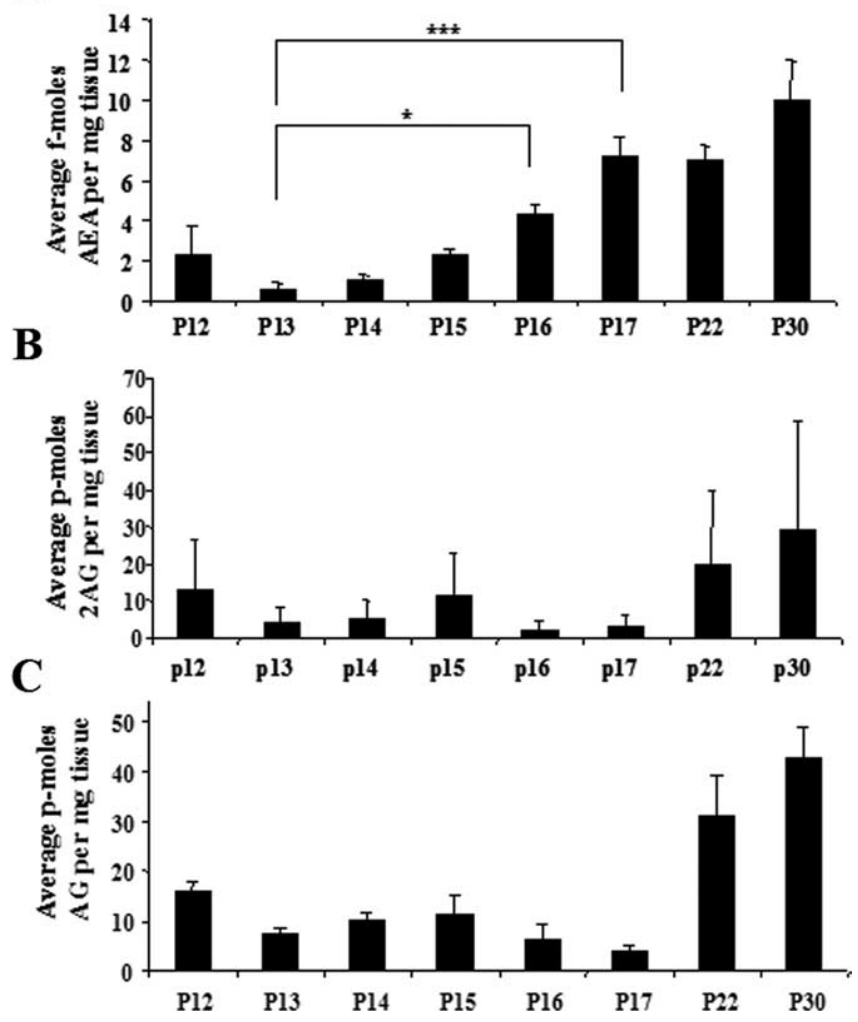

Figure 2. AEA but not 2-AG levels increase during postnatal development in striatal tissue. Endocannabinoids were extracted from tissue slices and analyzed using HPLC and mass spectrometry. Endocannabinoid levels are expressed as femtomoles or picomoles per milligram of wet tissue. A, AEA levels increase $1125 \%$ between P13 and P17, the two ages where LTP (P13) and LTD (P17) are consistently seen in the DL striatum. $\boldsymbol{B}, \boldsymbol{C}$, No developmental changes in striatal levels of $2-A G(B)$ or total $A G(2-A G$ and $1-A G$ combined; $\boldsymbol{C}) .{ }^{*} p<0.01 ;{ }^{* * *} p<0.001$. The $n$ values for each age group are as follows: P12, 10; P13, 14; P14, 22; P15, 14; P16, 9, P17, 11; P22, 4; P30, 6. Error bars indicate SEM.

formed analysis of protein levels in a separate set of slices. The results indicate that protein levels increase by only $15 \pm 5 \%$ between P12 and P17 ( $p>0.05$ student's $t$ test; $n=4$ for each group). Therefore, even when increases in tissue protein content are taken into account, the developmental increase in AEA levels is dramatic and suggestive of increased AEA production by striatal cells.

\section{CB1 agonist WIN 55,212 produces comparable inhibition of} striatal field potentials throughout development

Although we had observed a significant increase in striatal AEA at the critical period for the shift in DL striatal plasticity, it was unknown whether the CB1 receptors were present and fully functional in the DL striatum of the P13 animals. The developmental shift from LTP to cannabinoid-dependent LTD could be easily attributed to an upregulation of either CB1 receptor numbers or efficacy. To test the presence and efficacy of the receptors, we recorded field potentials and their response to application of the CB1-selective agonist WIN 55,212-2 (3 $\mu \mathrm{M}$ ) (Fig. 3). The average population spike amplitude in the $\mathrm{P} 13$ rats after this treatment was reduced to $46 \pm 7 \%(p<0.001 ; n=7)$ of the average baseline recording. The older animals (P16-P24) showed a similar maximal reduction with an average PS amplitude of $56 \pm 6 \%$ of baseline $(p<0.001 ; n=6)$, indicating that there is no significant difference in the response to $\mathrm{CB} 1$ receptor activation between the two age groups $(p>0.05)$. 


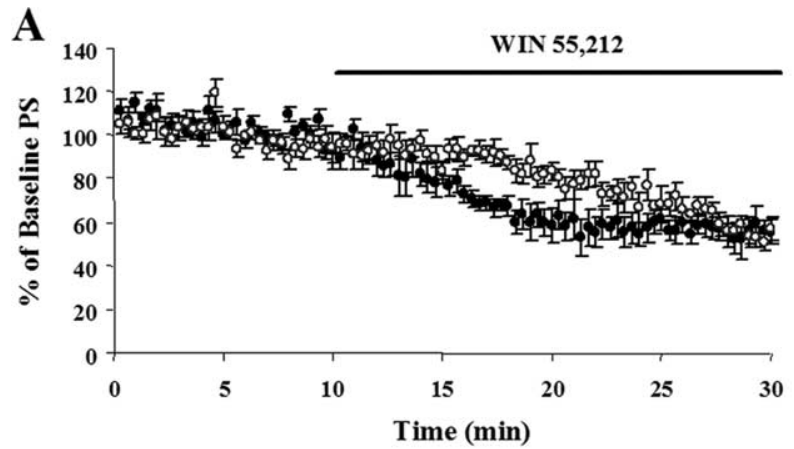

B

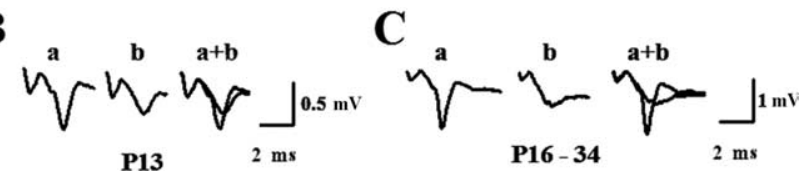

Figure 3. Response to a CB1 agonist is similar in P13 and in P16-P34 animals. $\boldsymbol{A}$, Normalized time course demonstrating depression of the PS amplitude in response to $3 \mu \mathrm{M}$ WIN 55,212 in slices from $\mathrm{P} 13$ rats $(\bigcirc)$ with an average response $46 \pm 7 \%$ of the baseline $(p<0.001 ; n=$ 7) and P16-P34 rats ( ) with an average of $56 \pm 6 \%$ of baseline $(p<0.001 ; n=6)$ after 20 min of application. $\boldsymbol{B}, \boldsymbol{C}$, Representative traces (averages of 12 individual responses). Traces represent responses during the baseline period (a), after 20 min application of $3 \mu \mathrm{M}$ WIN 55,212 (b), and overlay $(a+b)$. Error bars indicate SEM.

\section{Exogenous anandamide during HFS permits LTD induction in $\mathrm{P} 13$ rats}

The observations described in the preceding paragraph indicate that $\mathrm{CB} 1$ receptors are present and fully functional in $\mathrm{P} 13$ animal slices. Thus, we wanted to determine whether supplementing the low levels of AEA in slices early in development would allow for LTD induction. We reasoned that application of AEA in conjunction with HFS might lead to LTD induction in P13 rat slices. We bath applied $40 \mu \mathrm{M}$ AEA in aCSF that contained $0.5 \mathrm{mg} / \mathrm{ml}$ BSA and $0.1-0.2 \%$ DMSO for 25 min before HFS. The application of AEA did not significantly change the population spike amplitude. However, the HFS protocol in the presence of $40 \mu \mathrm{M}$ AEA induced LTD in five of five slices such that the post-HFS PS amplitude averaged $59 \pm 6 \%$ of the baseline measure $(p<0.001)$ (Fig. 4). AEA also serves as an endogenous ligand for both the transient receptor potential cation channel V1 (TRPV1) (Di Marzo et al., 2002) and the CB2 receptor, which was previously found in the brain (Gong et al., 2006). However, it appears that AEAfacilitated LTD in P13 animals is mediated via the CB1 receptor. Coapplication of the CB1-selective antagonist SR $141716(3 \mu \mathrm{M})$ with $40 \mu \mathrm{M}$ AEA prevented HFS-induced LTD and allowed for LTP induction (the average post-HFS PS amplitude was $139+$ $13 \%$ of baseline measure; $p<0.001 ; n=4$ ) (Fig. 4).

Interestingly, whereas the CB1 agonist WIN 55,212 was able to reduce the population spike amplitude (Fig. 3), application of exogenous AEA did not reduce the PS amplitude in nine of 10 slices. In one slice, wash-on of AEA induced an initial depression of $42 \%$, but the PS amplitude returned to the baseline level within the 25 min of pre-HFS recording. Furthermore, it appears that inducing LTD in the P13 animals does not induce changes that prohibit subsequent induction of LTP. In three slices that had been treated with AEA and given HFS, we imposed a $1 \mathrm{~h}$ washout period after LTD induction and then delivered a second HFS protocol. This post-washout HFS induced an increase in PS amplitude (average, 142\% of baseline). This finding also indicates that the effect of exogenous AEA is reversible.
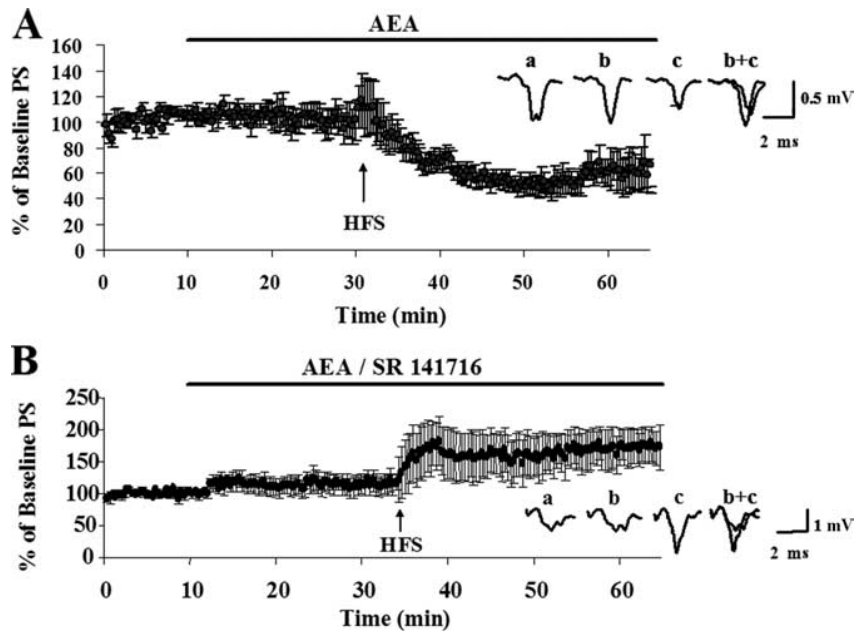

Figure 4. Activation of $C B 1$ receptors during HFS induces $L T D$ in the dorsolateral striatum of P13 rats. $A$, Time course showing normalized average of PS amplitudes in response to $40 \mu \mathrm{M}$ AEA and HFS. In P13 rats, the average response 30 min after HFS in the presence of $40 \mu \mathrm{M}$ AEA was $59 \pm 6 \%$ of the baseline measure $(p<0.001 ; n=5)$. Inset shows representative traces (average of 12 individual responses) from a typical experiment. Traces represent responses during the baseline period (a), in the presence of $40 \mu \mathrm{m}$ AEA (b), $30 \mathrm{~min}$ after HFS in the presence of $40 \mu \mathrm{m} A E A(c)$, and overlay $(b+c)$. $\boldsymbol{B}$, Time course showing normalized average PS amplitudes in response to a coapplication of $40 \mu \mathrm{m}$ AEA and $3 \mu \mathrm{m}$ SR 141716 and HFS. The average response $30 \mathrm{~min}$ after HFS was $139+13 \%$ of the baseline measure $(p<0.001 ; n=$ 4). Inset shows representative traces (average of 12 individual responses) from a typical experiment. Traces represent responses during the baseline period (a), in the presence of $40 \mu \mathrm{M} A E A$ and $3 \mu \mathrm{m}$ SR 141716 (b), 30 min after HFS in the presence of $40 \mu \mathrm{m}$ AEA and $3 \mu \mathrm{m}$ SR 141716 (c), and overlay $(b+c)$. Error bars indicate SEM.

\section{Blocking CB1 receptors during HFS results in LTP in rats $\mathrm{P} 15-\mathrm{P} 34$}

Previous studies using whole-cell electrophysiological recordings have shown that antagonists of the $\mathrm{CB} 1$ receptor block the induction of striatal LTD (Gerdeman et al., 2001; Ronesi et al., 2004). We sought to replicate these findings in P15-P34 rat brain slices using extracellular field-potential recordings as additional evidence for an endocannabinoid role in striatal LTD. Application of $3 \mu \mathrm{M}$ SR 141716 for 25 min before giving the HFS did not alter PS amplitude. The average PS amplitude after $25 \mathrm{~min}$ of SR 141716 application equaled $106 \pm 1 \%$ of the predrug baseline $(p=0.06)$. However, subsequent delivery of HFS in the presence of $3 \mu \mathrm{M}$ SR 141716 induced an increase in PS amplitude (155 \pm $23 \%$ of baseline; $n=6 ; p<0.001$ ) (Fig. 5 ).

\section{Blockade of 2-AG synthesis during HFS does not interfere} with HFS-induced striatal LTD in P16-P32 rats

Although the field recordings demonstrated that LTD induction was likely a result of changes in endocannabinoid release rather than receptor expression levels and the endocannabinoid measurements suggested that the developmental increase in striatal AEA was likely the source, we could not discount a potential role for 2-AG. Indeed, previous studies have indicated that endocannabinoid-dependent LTD in the cerebellum and hippocampus is mediated by 2-AG (Chevaleyre and Castillo, 2003; Safo and Regehr, 2005). Endocannabinoid measurement in striatal tissue punches after HFS was not a viable option because of sensitivity limitations of the mass spectrometer for AEA detection and the lack of information about the total tissue area that is innervated by the fibers we stimulate in a striatal slice. Therefore, we used the DAG lipase inhibitor THL (Orlistat) that has been shown to block synthesis of 2-AG (Bisogno et al., 2006) to deter- 
A

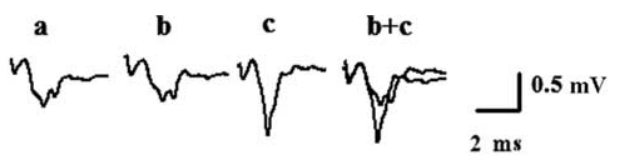

B

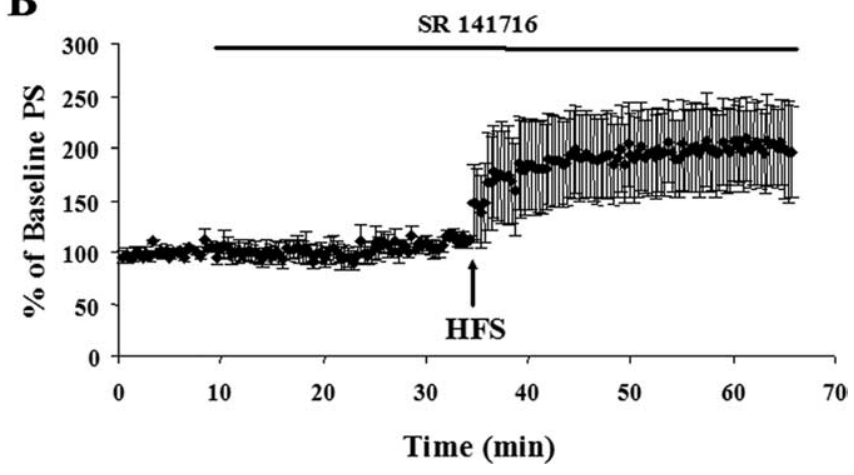

Figure 5. Blocking $C B 1$ receptors during HFS leads to LTP in the dorsolateral striatum of rats P16-P36. A, Representative traces (average of 12 individual responses) from a typical experiment. Traces represent response during the baseline period (a), in the presence of $3 \mu \mathrm{M} \mathrm{SR}$ 141716 (b), 30 min after HFS in the presence of $3 \mu \mathrm{MSR} 141716$ (c), and overlay (b+c). B. Time course demonstrating that HFS in the presence of $3 \mu \mathrm{M}$ SR 141716 induces LTP in P16 -P36 rats. The average response $30 \mathrm{~min}$ after HFS in the presence of $3 \mu \mathrm{m}$ SR 141716 was $155 \pm 23 \%$ of the baseline measure $(p<0.001 ; n=6)$. Error bars indicate SEM.

\section{A}
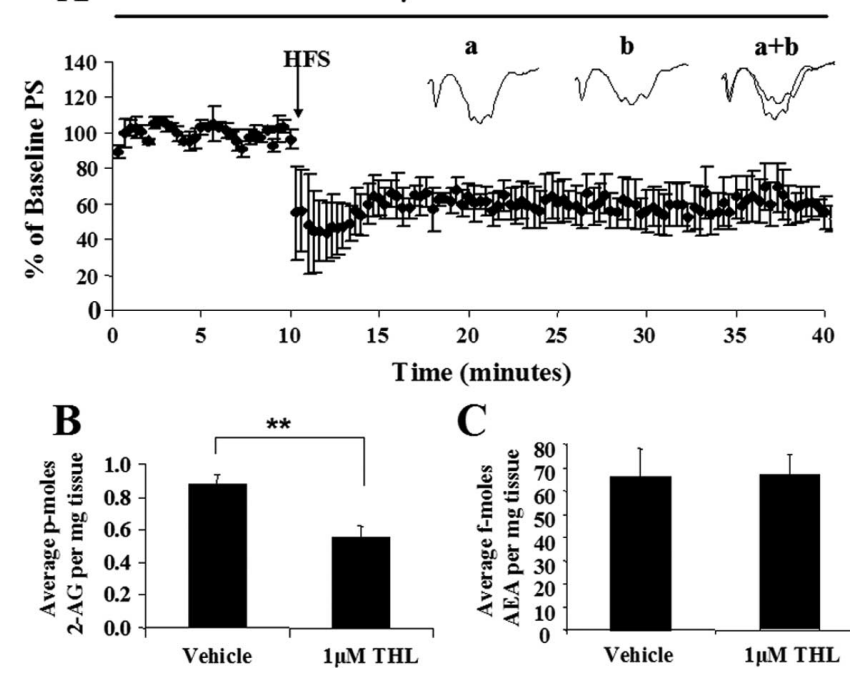

C

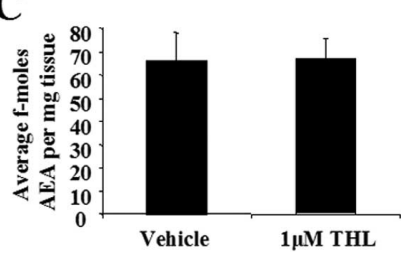

Figure 6. Striatal LTD does not depend on 2-AG synthesis. A, Time-course plot for experiments examining THL effects on striatal LTD. Note that inhibition of 2-AG synthesis does not alter HFS-induced LTD. Slices were exposed to $1 \mu \mathrm{m}$ THL for $60-120 \mathrm{~min}$ before and throughout the duration of the field recordings. The average response $30 \mathrm{~min}$ after HFS in the presence of 1 $\mu \mathrm{M}$ THL was $60 \pm 10 \%$ of the baseline measure $(n=4)$. The inset provides representative traces (average of 12 individual responses from a typical experiment). Traces represent response during the baseline period in the presence of $1 \mu \mathrm{m}$ THL (a), 30 min after HFS in the presence of $1 \mu \mathrm{m}$ THL (b), and overlay $(a+b)$. To ensure the efficacy of the drug to inhibit 2-AG synthesis, corticostriatal slices were treated with $1 \mu \mathrm{M}$ THL or vehicle for $1 \mathrm{~h}$. The striatum was dissected out and endocannabinoids were extracted and analyzed using HPLC and mass spectrometry. $B, C$, One micromolar THL reduced basal levels of $2-A G$ to $63 \%$ of the vehicle controls $(\boldsymbol{B})\left({ }^{* *} p<0.005\right)$ but had no effect on basal levels of AEA (C). Error bars indicate SEM.

mine the role of 2-AG in striatal LTD. For this purpose, slices were preincubated with $1 \mu \mathrm{M}$ THL for $60-120 \mathrm{~min}$ before recording and the HFS recordings were done in the continuous presence of this concentration of THL. Figure 6 demonstrates that $1 \mu \mathrm{M}$ THL did not have a significant effect on LTD induction or expres- sion in the DL striatum (average post-HFS PS amplitude was $59 \pm 10 \%$ of the baseline measure; $n=5$ ). To ensure that $1 \mu \mathrm{M}$ THL was indeed reducing 2-AG synthesis in the slice, corticostriatal slices were treated with $1 \mu \mathrm{M}$ THL for $60 \mathrm{~min}$; the striatal tissue was subsequently dissected out and the endocannabinoid content was extracted and measured. THL treatment reduced basal levels of striatal 2-AG to $63 \%(p<0.005)$ relative to vehicle control levels ( $n=6$ per group) (Fig. $6 B$ ). THL had no effect on levels of AEA (Fig. 6C).

\section{Discussion}

In the present study, we provide evidence that striatal AEA levels increase during the third postnatal week in rats and that this increase contributes to the shift in HFS-induced long-term synaptic efficacy from LTP to LTD in the DL striatum. We have shown that whereas $\mathrm{CB} 1$ receptors are present and fully functional in the DL striatum in P13 rats, AEA levels in the striatum increase $>11$-fold between postnatal days 13 and 17 . We have demonstrated that exogenously applying AEA during HFS allows for induction of LTD in striatal slices from P13 rats, whereas blockade of CB1 receptors during HFS allows for induction of LTP in rats P16-P36. Additionally, blockade of 2-AG synthesis could not prevent induction of striatal LTD. Together, these results suggest that all other necessary elements required for both LTP and LTD are in place by P13, and the presence or absence of AEA is the important determining factor for the shift in striatal plasticity.

Our findings support the idea that striatal LTD requires combined CB1 receptor activation and repetitive afferent activation. Afferent activation alone is not sufficient to induce LTD, as shown by the fact that HFS induces no depression when AEA levels are low or when CB1 receptors are blocked. Activation of CB1 receptors alone does not induce LTD, as we have shown in the past (Ronesi et al., 2004) (but see Kreitzer and Malenka, 2005). The observation that application of AEA without HFS does not induce LTD is consistent with this idea. In this context, it is surprising that AEA alone does not produce a decrease in PS amplitude similar to that induced by WIN 55,212 and other synthetic CB1 agonists (Gerdeman and Lovinger, 2001, Gerdeman et al., 2002). However, AEA is a partial agonist at the CB1 receptor (Sugiura et al., 1999) and thus may not produce receptor activation strong enough to inhibit transmission on its own.

Our suggestion that AEA is involved in striatal LTD agrees with previous studies. Striatal LTD has been shown to depend on dopamine D2 receptor activation (Calabresi et al., 1992a, 1997; Tang et al., 2001), and in vivo studies have shown that D2 receptor stimulation by systemic administration of the $\mathrm{D} 2$ receptor agonist quinpirole increases the release of AEA but not 2-AG in striatum of freely moving rats (Giuffrida et al., 1999). We have replicated these findings in slices and shown a similar increase in synthesis of AEA, but not 2-AG, in response to bath application of quinpirole in high potassium, and that this effect can be blocked by the D2 receptor antagonist sulpiride (Ade et al., 2003). Another previous report has provided evidence that sulpiride can also completely block synaptically driven endocannabinoidmediated striatal LTD (Kreitzer and Malenka, 2005). In concordance with these findings, $D 2-/-$ mice show HFS-induced LTP whereas D2+/+ animals exhibit LTD (Calabresi et al., 1997). Furthermore, previous work suggests that striatal D2 receptor activation relieves a cholinergic tone that normally prevents endocannabinoid production (Wang et al., 2006). Therefore, we suggest that, during HFS, dopamine D2 receptor stimulation with concurrent depolarization of the striatal medium spiny neu- 
rons contributes to AEA synthesis and release that activates CB1 receptors and, in cooperation with other factors, induces LTD.

Although AEA also serves as an agonist for the TRPV1 receptor (Di Marzo et al., 2002), it is unlikely that activation of TRPV1 by the exogenously applied AEA was responsible for the HFSinduced LTD seen in the P13 rats because coapplication of a CB1 selective antagonist fully blocked the effects. Furthermore, striatal LTD is not blocked by the TRPV1 antagonist capsazepine (J. Ronesi and D. Lovinger, unpublished observation).

It is possible that the exogenous AEA present in our experiment synergizes with another endocannabinoid present in young striatal slices. In this context, it was worthwhile considering the potential role of 2-AG in striatal LTD. However, we did not observe any developmental changes in striatal 2-AG expression either when analyzed alone or in combination with its isomer 1-AG. Levels of 2-AG are $~ 1000$-fold higher than AEA in the striatum, and 2-AG synthesis has been implicated in retrograde signaling and LTD at other brain synapses (Stella et al., 1997; Chevaleyre and Castillo, 2003; Kim and Alger, 2004; Safo and Regehr, 2005). However, 2-AG is both an end product for one enzymatic pathway and a precursor for other pathways in lipid metabolism (Piomelli, 2003). Therefore, a developmental increase in the pool of 2-AG used for retrograde signaling might be masked by the existence of a much larger pool of 2-AG used for other cellular processes. Therefore, we investigated the role of 2-AG in HFS-induced LTD by inhibiting its synthesis with the DAG lipase inhibitor THL and found that this inhibition did not affect striatal LTD. However, these results may be explained by the fact that the striatum has unique circuitry and receptor expression patterns, which may preferentially promote the synthesis of AEA as opposed to 2-AG as a result of HFS. In fact, one study has shown previously that, unlike other regions, strong depolarization of the medium spiny neurons in the striatum is not sufficient to induce endocannabinoid release (Kreitzer and Malenka, 2005), further suggesting that endocannabinoid signaling in the striatum differs from that in other brain regions.

Striatal medium spiny neurons undergo a number of major morphological and physiological changes during the developmental period in which we observe the shift in striatal plasticity. These changes include synaptogenesis and dendritic spine formation, which may drive the developmental increase in AEA synthesis. At the onset of the third postnatal week, the striatal GABAergic medium spiny neurons begin to establish their spiny appearance (Tepper et al., 1998) and there is a dramatic increase in the number of axospinous synapses (Sharpe and Tepper, 1998). The spine neck serves as a barrier to prevent elevations of intracellular $\mathrm{Ca}^{2+}$ that may occur from synaptic transmission from spilling over to the rest of the dendrite (Nimchinsky et al., 2002). Because endocannabinoid synthesis is driven by calcium influx (Di Marzo et al., 1994), the formation of the dendritic spines may allow for synapse-specific AEA synthesis and retrograde signaling to occur.

Previous results from whole-cell voltage-clamp studies have shown that blocking $\mathrm{CB} 1$ receptors inhibits the expression of LTD (Gerdeman et al., 2002, Ronesi et al., 2004) and, thus, we expected similar results in the field-potential recordings. However, SR 141716 not only blocked the HFS-induced LTD in the P16-P36 animals, but it allowed for the induction of LTP. We suspect the discrepancy between these previous results and our own derives from the different techniques used to assess synaptic efficacy. Signaling molecules essential for the induction of LTP may diffuse out of the cell into the recording electrode in the whole-cell experiments (Partridge et al., 2000). Because there is no disruption of the plasma membrane in the extracellular recordings, these signaling molecules would remain intact, thus allowing for LTP induction.

The fact that both LTP and LTD can be expressed at all ages depending on CB1 receptor activation could suggest a "yin/yang" relationship between the two forms of plasticity. That is, synapses are always capable of expressing either form of plasticity, and the form expressed may simply depend on the number and efficacy of certain key signaling molecules such as endocannabinoids for LTD or glutamate for LTP. Additionally, cortical inputs activate fast-spiking GABAergic interneurons with a shorter latency than seen in medium spiny neurons (Mallet et al., 2005), and this may also reduce LTP induction (Smith et al., 2001). Both postsynaptic NMDA receptors (which promote LTP) and presynaptic CB1 receptors (which promote LTD) could be activated during HFS. If the cannabinoid-signaling pathway predominates, then LTD would likely follow HFS. Conversely, if the effect of NMDA receptor activation predominates, then LTP would likely follow HFS. Alternatively, molecules involved in expression of one form of plasticity may actively suppress expression of the other plastic change. For example, CB1 receptor activation by endocannabinoids suppresses presynaptic release of glutamate from the cortical terminals (Gerdeman and Lovinger, 2001; Huang et al., 2001). The lower release probability may result in a decreased number of NMDA receptors activated during the stimulus train, thus inhibiting NMDA receptor-dependent striatal LTP (Calabresi et al., 1992a; Partridge et al., 2000), and promoting LTD induction (Calabresi et al., 1992b; Choi and Lovinger, 1997) (for an alternative view, see Spencer and Murphy, 2000).

Previous studies have demonstrated that the CB1 antagonist rimonabant (SR 141716) can aid in smoking cessation (Frishman et al., 2006). Striatal function has been implicated in both drug addiction and habit formation, and striatal LTD could be part of this process (Gerdeman et al., 2003). Our observation that blocking CB1 receptors may allow for striatal LTP provides a possible mechanistic explanation for the efficacy of rimonabant in smoking cessation because a long-term increase in synaptic excitation of striatal medium spiny neurons would enhance their inhibitory influence over basal ganglia activity. Thus, in addition to participating in development of striatal synaptic circuitry, the balance between striatal LTD and LTP may play a role in the addiction process.

\section{References}

Ade K, Harvey-White J, Kunos G, Lovinger DM (2003) Stimulation of dopamine D2 receptors induces the formation of anandamide (AEA) but not 2-arachidonoyl glycerol (2-AG) in rat cortical-striatal slices. Int Cannabinoid Res Soc Abstr 13:88.

Barnes TD, Kubota Y, Hu D, Jin DZ, Graybiel AM (2005) Activity of striatal neurons reflects dynamic encoding and recording of procedural memories. Nature 437:1158-1161.

Berrendero F, Sepe N, Ramos JA, Di Marzo V, Fernandez-Ruiz J (1999) Analysis of cannabinoid receptor binding and mRNA expression and endogenous cannabinoid contents in the developing rat brain during late gestation and early postnatal period. Synapse 33:181-191.

Bisogno T, Cascia MG, Saha B, Mahadevan A, Urbani P, Minassi A, Appendino G, Saturnino C, Martin B, Razdan R, Di Marzo V (2006) Development of the first potent and specific inhibitors of endocannabinoid biosynthesis. Biochim Biophys Acta 1761:205-212.

Calabresi P, Maj R, Pisani A, Mercuri NB, Bernardi G (1992a) Long-term synaptic depression in the striatum: physiological and pharmacological characterization. J Neurosci 12:4224-4233.

Calabresi P, Pisani A, Mercuri NB, Bernardi G (1992b) Long-term potentiation in the striatum is unmasked by removing the voltage-dependent magnesium block of the NMDA receptor channels. Eur J Neurosci 4:929-935. 
Calabresi P, Pisani A, Mercuri NB, Bernardi G (1994) Post-receptor mechanisms underlying striatal long-term depression. J Neurosci 14:4871-4881.

Calabresi P, Saiardi A, Baik JH, Centonze D, Mercuri NB, Bernardi G, Borrelli E (1997) Abnormal synaptic plasticity in the striatum of mice lacking dopamine D2 receptors. J Neurosci 17:4536-4544.

Chevaleyre V, Castillo PE (2003) Heterosynaptic LTD of hippocampal GABAergic synapses: a novel role of endocannabinoids in regulating excitability. Neuron 38:461-472.

Choi S, Lovinger DM (1997) Decreased probability of neurotransmitter release underlies striatal long-term depression and postnatal development of corticostriatal synapse. Proc Natl Acad Sci USA 94:2665-2670.

Costa RM, Cohen D, Nicolelis MA (2004) Differential corticostriatal plasticity during fast and slow motor skill learning in mice. Curr Biol 14:1124-1134.

Di Marzo V (1999) Biosynthesis and inactivation of endocannabinoids: relevance to their proposed role as neuromodulators. Life Sci 65:645-655.

Di Marzo V, Fontana A, Cadas H, Schinelli S, Cimino G, Schwartz JC, Piomelli D (1994) Formation and inactivation of endogenous cannabinoid anandamide in central neurons. Nature 372:686-691.

Di Marzo V, De Petrocellis L, Fezza F, Ligresti A, Bisogno T (2002) Anandamide receptors. Prostaglandins Leukot Essent Fatty Acids 66:377-391.

Felder CC, Briley EM, Axelrod J, Simpson JT, Mackie K, Devane WA (1993) Anandamide, an endogenous cannabimimetic eicosanoid, binds to the cloned human cannabinoid receptor and stimulates receptor-mediated signal transduction. Proc Natl Acad Sci USA 90:7656-7660.

Fernández-Ruiz J, Berrendero F, Hernandez ML, Ramos JA (2000) The endogenous cannabinoid system and brain development. Trends Neurosci 23:14-20.

Frishman WH, Mitta W, Kupersmith A, Ky T (2006) Nicotine and nonnicotine smoking cessation pharmacotherapies. Cardiol Rev 14:57-73.

Gerdeman G, Lovinger DM (2001) CB1 cannabinoid receptor inhibits synaptic release of glutamate in rat dorsolateral striatum. J Neurophysiol 85:468-471.

Gerdeman GL, Ronesi J, Lovinger DM (2002) Postsynaptic endocannabinoid release is critical to long-term depression in the striatum. Nat Neurosci 5:446-451.

Gerdeman GL, Partridge JG, Lupica CR, Lovinger DM (2003) It could be habit forming: drugs of abuse and striatal synaptic plasticity. Trends Neurosci 26:184-192.

Giuffrida A, Parsons LH, Kerr TM, Rodriguez de Fonesca F, Navarro M, Piomelli D (1999) Dopamine activation of endogenous cannabinoid signaling in dorsal striatum. Nature Neurosci 2:358-363.

Giuffrida A, Rodriguez de Fonesca F, Piomelli D (2000) Quantification of bioactive acylethanolamides in rat plasma by electrospray mass spectrometry. Anal Biochem 280:87-93.

Gong JP, Onaivi ES, Ishiguro H, Liu QR, Tagliaferro PA, Brusco A, Uhl GR (2006) Cannabinoid CB2 receptors: immunohistochemical localization in rat brain. Brain Res 1071:10-23.

Gubellini P, Saulle E, Centonze D, Bonsi P, Pisani A, Bernardi G, Conquet F, Calabresi P (2001) Selective involvement of $\mathrm{mGlu} 1$ receptors in corticostriatal LTD. Neuropharmacology 40:839-846.

Huang CC, Lo SW, Hsu KS (2001) Presynaptic mechanisms underlying cannabinoid inhibition of excitatory synaptic transmission in rat striatal neurons. J Physiol (Lond) 532:731-748.

Kerr JN, Wickens JR (2001) Dopamine D-1/D-5 receptor activation is required for long-term potentiation in the rat neostriatum in vitro. J Neurophysiol 85:117-124.

Kim J, Alger BE (2004) Inhibition of cyclooxygenase-2 potentiates retrograde endocannabinoid effects in hippocampus. Nat Neurosci 7:697-698.
Kreitzer AC, Malenka RC (2005) Dopamine modulation of state-dependent endocannabionoid release and long-term depression in the striatum. J Neurosci 25:10537-10545.

Mallet N, Le Moine C, Charpier S, Gonon F (2005) Feedforward inhibition of projection neurons by fast-spiking GABA interneurons in the rat striatum in vivo. J Neurosci 25:3857-3869.

Nimchinsky E, Sabatini B, Svoboda K (2002) Structure and function of dendritic spines. Annu Rev Physiol 64:313-353.

Lovinger DM, Tyler EC, Merritt A (1993) Short- and long-term synaptic depression in rat neostriatum. J Neurophysiol 70:1937-1949.

Partridge J, Tang KC, Lovinger DM (2000) Regional and postnatal heterogeneity of activity-dependent long-term changes in synaptic efficacy in the dorsal striatum. J Neurophysiol 84:1422-1429.

Piomelli D (2003) The molecular logic of endocannabinoid signaling. Nat Rev Neurosci 4:873-884.

Reynolds JN, Hyland BI, Wickens JR (2001) A cellular mechanism of reward-related learning. Nature 413:67-70.

Ronesi J, Gerdeman GL, Lovinger DM (2004) Disruption of endocannabinoid release and striatal long-term depression by postsynaptic blockade of endocannabinoid membrane transport. J Neurosci 24:1673-1679.

Safo PK, Regehr WG (2005) Endocannabinoids control the induction of cerebellar LTD. Neuron 48:647-659.

Sharpe NA, Tepper JM (1998) Postnatal development of excitatory synaptic input to the rat neostriatum: an electron microscopic study. Neuroscience 84:1163-1175.

Smith R, Musleh W, Akopian G, Buckwalter G, Walsh JP (2001) Regional differences in expression of corticostriatal synaptic plasticity. Neuroscience 106:95-101.

Spencer JP, Murphy KP (2000) Bi-directional changes in synaptic plasticity induced at corticostriatal synapses in vitro. Exp Brain Res 135:497-503.

Stella N, Schweitzer P, Piomelli D (1997) A second endogenous cannabinoid that modulates long-term potentiation. Nature 388:773-778.

Sugiura T, Kodaka T, Nakane S, Miyashita T, Kondo S, Suhara Y, Takayama H, Waku K, Seki C, Baba N, Ishima Y (1999) Evidence that the cannabinoid CB1 receptor is a 2 -arachidonoylglycerol receptor. Structureactivity relationship of 2-arachidonoylglycerol, ether-linked analogues, and related compounds. J Biol Chem 274:2794-2801.

Sung K, Choi S, Lovinger DM (2001) Activation of group I mGluRs is necessary for induction of long-term depression at striatal synapses. J Neurophysiol 86:2405-2412.

Tang KC, Low MJ, Grandy DK, Lovinger DM (2001) Dopamine-dependent synaptic plasticity in striatum during in vivo development. Proc Natl Acad Sci USA 98:1255-1260.

Tepper JM, Sharpe NA, Koos TZ, Trent F (1998) Postnatal development of the rat neostriatum: electrophysiological, light- and electron-microscopic studies. Dev Neurosci 20:124-145.

Wang L, Liu J, Harvey-White J, Zimmer A, Kunos G (2003) Endocannabinoid signaling via cannabinoid receptor 1 is involved in ethanol preference and its age-dependent decline in mice. Proc Natl Acad Sci USA 100:1393-1398.

Wang Z, Kai L, Day M, Ronesi J, Yin HH, Ding J, Tkatch T, Lovinger DM, Surmeier DJ (2006) Dopaminergic control of corticostriatal long-term synaptic depression in medium spiny neurons is mediated by cholinergic interneurons. Neuron 50:443-452.

Yin HH, Ostlund SB, Knowlton BJ, Balleine BW (2005) The role of the dorsomedial striatum in instrumental conditioning. Eur J Neurosci 22:513-523.

Yin HH, Knowlton BJ, Balleine BW (2006) Inactivation of dorsolateral striatum enhances sensitivity to changes in the action-outcome contingency in instrumental conditioning. Behav Brain Res 166:189-196. 